\title{
A Study on Flexible Cluster Units for Refugees Camps
}

\author{
By Maamoun Ammoun ${ }^{1}$ Kozan Uzunoğlu ${ }^{2 *}$
}

\begin{abstract}
According to the UNHCR reports in 2017, 65.3 million people are forced to migrate away from their homes. The other dramatic identification is that 22.5 million refugees had to survive in other countries in refugee camps. The shelters that are used in these camps are most of the time temporary shelters which are used during natural disasters (earthquakes, fire, floods, etc.). However, it has been proved that refugees spend minimum 5 years in these camps. Some records mention that 2 generations may spend their lives in these inhumane conditions of camps. All these problems force the review the organization of refugee camps deeply from the architectural point of view. Conceptually, flexibility in architecture basically aims to satisfy physical and psycho-social needs of users. In this study, the design principles of sustainable refugee camps were discussed and flexible design of shelters and clusters considering different family sizes and family needs were developed.
\end{abstract}

Keywords: Refugee camps; refugees' needs; modular shelters; flexibility in architecture; refugee shelter clusters

\section{Introduction}

In order to mention the importance of the subject, it will be useful to give examples from the near history. In 2011, over 6.5 million Syrians have been displaced because of the civil war in Syria. Two million of them have fled to neighboring countries. The United Nations High Commissioner for Refugees (UNHCR) says another 6 million have been displaced within Syria itself since the start of the conflict (UNHCR, 2014), which force them to risk their lives on the way to Europe hopping to find any place to live. However, they do not have any choices, no food, no water, but damaged houses. This homelessness naturally will cause a very serious disease, specially using polluted water and unclean expired food. Some of expected diseases are (cholera, microbial infections, kidney diseases, psychotic diseases and depression, etc.). Refugee's camps need electric station, tons of water tanks, and special equipment shelters in order to be livable. That is a huge budget for countries like Lebanon and Jordan. That reflects why always refugees situation are becoming worse day by day. A growing number of Syrian refugees are escaping across the border into Turkey, and then hundreds of thousands of them decide to go on the "Death Trip" to Europe across the Mediterranean Sea from Turkey to Greece, seeking for better live and safer homes. Unfortunately, thousands of them were drowned, and couldn't make it. Internal displaced people inside Syria are not less important or less numbers than the international refugees. According to IDMC shows that over than 6,600,000 had internally displaced (Figure 1). 


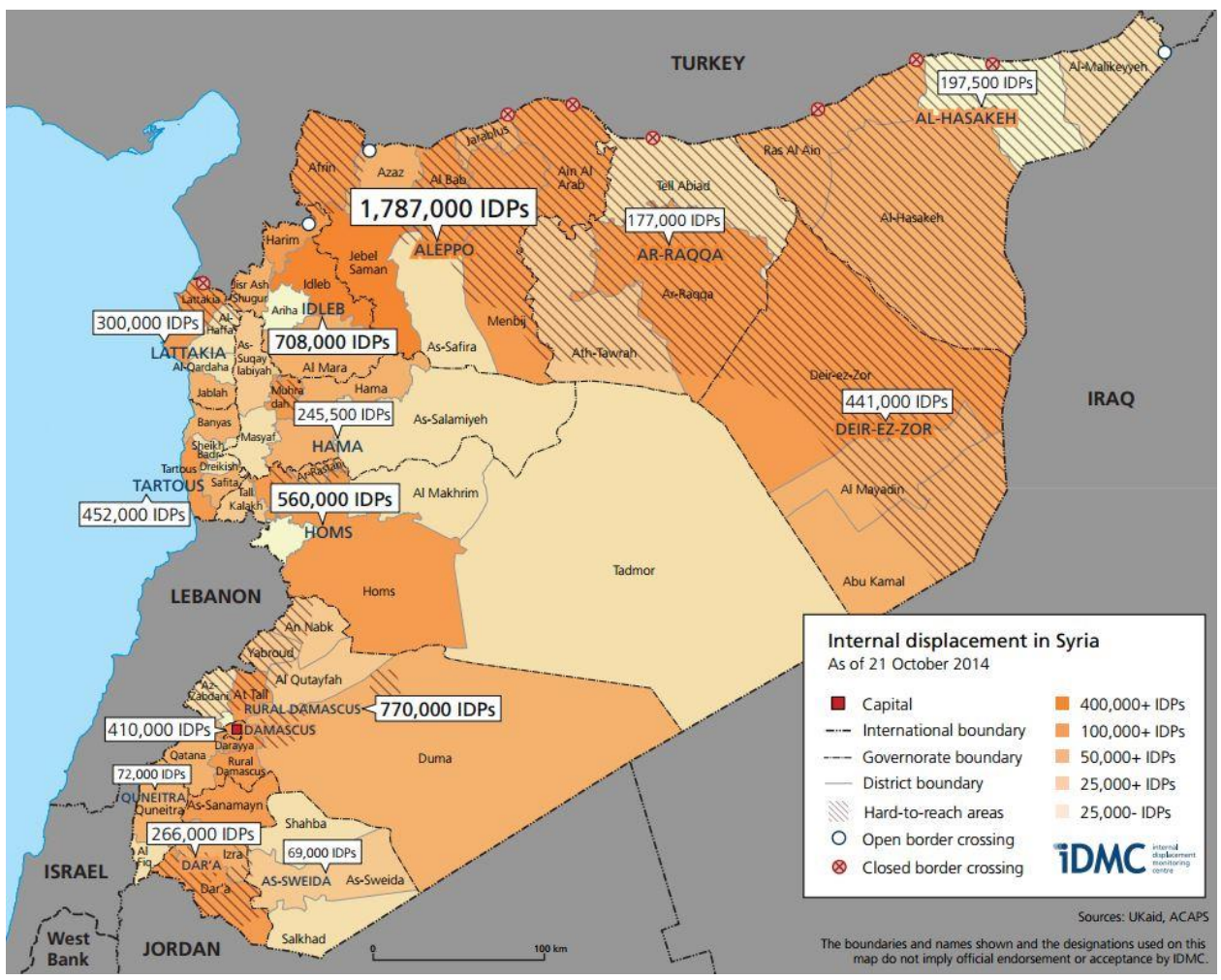

Figure 1: Internal displacement in Syria (Internal Displacement Monitoring Centre, 2014)

All of those facts and numbers mentioned above definitely force to overview the planning of refugees' camps again and again from the architectural point of view. In other words, refugee camps should be reconsidered economically, socially and environmentally. Modularly developed shelter units for flexible cluster arrangements can be useful tool in order to overcome these problems. Shelters in most of the refugee's camps do not satisfy people's physical and psycho-social needs. Temporary shelters that are widely used in the camps do not create loyalty on people and most of them are insufficient for long term use. On the other hand, UNHCR states that all refugees have the right of living in safe shelters which provide opportunity for storing their goods, space for privacy and emotional needs. It's also refugees right to have common spaces for their social needs. Meanwhile the other important point is that refugees' camps bring heavy economic burden for the countries.

There are recent studies about refugee shelters in literature. Hasgül and Özsoy (2017) examined transient, modular and flexible solutions through classification while relating physical solutions with theoretical content. They made a comparative analysis of selected shelter projects. Oliveira and Campos (2019) proposed an emergency shelter, through the development of a modular system that is flexible and temporary. Different than the other studies, the aim of this study is to develop modular flexible shelter clusters for refugees such that they will satisfy both physical and psycho-social needs of their users. 


\section{Refugees Basic Needs \& Principles of Flexibility}

Different family sizes, different ages and/or different cultures create different physical and social needs. At this point, flexibility as a concept will be the main architectural tool to dominate these physical and social needs within the limited modular spaces. Refugees basic needs can well be answered in the Maslow's theory as user basic needs. Arcan, (1992) in his book mention's that, in reality, the user needs are abstract and unobservable concept. To understand the user needs, you should understand the relation between people and their behaviors. You should know the reasons for these behaviors. The main objective of the human behaviors is to meet/satisfy the basic needs. "Human needs" are very general concepts. The expectations of people from the environment who use the spaces we designed are called the user requirements in architecture. The user needs determine the minimum qualifications of a space. The lack of these qualifications of space may cause discomfort for the user and the intended use of space hampered. For example, hunger as a requirement is embodied in the act of eating. "User requirements", are the environmental conditions for the individuals or communities to perform their actions most effectively. User requirements depend on the human anthropometry, the sensory and perceptual dimensions. Refugees basic needs can also be examined under two headings, physical user needs and psychological - social user needs. Physical user needs are examined as spatial needs, thermal comfort needs, acoustical needs, optical needs, hygienic needs and security needs.

- Spatial Needs: The dimensions (static, dynamic and anthropometric), types of activities and related behaviours of people in space (Figure 2.1) for static, dynamic and anthropometric human dimensions

- Thermal Comfort Needs: Suitable, temperature, humidity and air movement in a space.

- Acoustical Needs: Sound intensity, transmission and reflection properties of the space.

- Optical Needs: Suitable light intensity and illumination level in a space.

- Hygienic Needs: Clean water, garbage and disposals, protection from germs and harmful organisms.

- Security Needs: The stability, protection against natural disasters (fire, earthquake), thiefs and accidents.

Psychological - social user needs are examined as; privacy needs, behavioral needs, aesthetic needs and social needs.

- Privacy Needs: Acoustical, visual, personal and social privacy.

- Behavioural Needs: Personal (45-120 cm),social (120-360cm),public (360-) spaces (Figure 2.4).

- Aesthetic Needs: Formal, textural and color features.

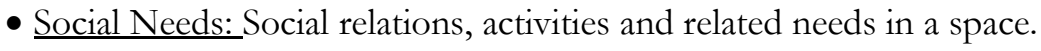

\section{Human Activities in Shelters and Life Cycle}

As mentioned before, UNHCR states that all refugees have the right of living in safe shelters like their homes. Therefore, in this study, activities in shelter can well be evaluated as activities in typical homes which provide opportunity for storing their 
goods, space for privacy and emotional needs. It's also refugees right to have common spaces for their social needs. Human activities in a refugee's shelter are as mentioned in (Table 1).

Table 1. Human activities in a refugee's shelter (Arcan, 1992).

\begin{tabular}{ll}
\hline Main Activity Group & Related Human Activities \\
\hline Resting & Sleeping, Resting, Idling, Nourishing \\
\hline Dining & Food Storing, Food Preparing, Eating \\
\hline Hygiene & Discharging, Bathing, Make - up, Sports \\
\hline Reproduction & Sexual intercourse, Infant care, Teenage care \\
\hline Dressing & Dressing, Dress maintenance and repair, Dress storing, Sewing \\
\hline Cleaning and & Household cleaning and repair, Dish washing, Laundry: washing, ironing \\
Repairing & and repair \\
\hline Culture and Education & Literacy, Homework, Communication means (TV, radio, computer, etc.) \\
\hline Entertainment & Music Play and dances, Hobbies \\
\hline External Relation & Communication (Telephone, PC, laptop, etc.), Guests - invitations, Food \\
& and household delivery \\
\hline Management & Planning, Control \\
\hline
\end{tabular}

"Life cycle" of a family (or household) in a long term stayed shelter or in camp is worth to examine. This is because; depending on time the number of household in a shelter may increase or decrease. The requirements of the users also vary depending on the age groups. Change of needs in a shelter during a life cycle can be due to;

- Increase in number of children; another room requirement because of gender differences in children

- Children's work; after a certain age they require a private space

- Increase of requirement for storage in a shelter as time passes and also for hobbies.

- When mother or father of one of the partners (married couple) has to live in the shelter together with them.

- Children (either married or single) leave of shelter.

- Death of grandparents.

- Parents leave the shelter.

UNHCR have mentioned that some families live in refugee camps for more than 20 years. So, in the light of these facts, it can be said that developing flexible shelter units which can adopt themselves to change of needs during life cycle is essential.

\section{Design Principles of Refugees Camps}

It is very important to have deep understanding of the main principles related to refugee camps design and planning, and learn the standards of them. Site selection is one of the first discussions that must be well studied by the authorities and the responsible organizations. A lot of considerations must be taken in respect, in order to select the most efficient site. One of these considerations is water, a site with no water resource available can't be chosen. The UNHCR has mentioned in "Handbook for Emergencies" that "A site should not be selected on the assumption that water can be found merely by 
drilling, digging, or trucking (Handbook for Emergencies 2007). As a general rule of thumb, no shelter should be more than 200 meters or a few minutes' walk away from a water distribution point. Additionally, there should be at least one tap per 80-100 refugees and no more than 200 refugees per hand pump. (Huynh, 2015). Safety must also be considered and the site must be mine free and ideally distant from borders and also far away from the conflicting regions. According to the UN standard, it is recommended that each person should have 45 square meters and no less than 30 square meters in the camp area. Transportation into and out the site must be suitable during all the seasons and must be well connected. Climate conditions can also influence the site selection process, Topography, and soil properties must be considered (UNHCR Emergency Handbook, 2007).

Site organization is another important subject. After the site had been selected, a studied plan must be set correctly and a well distributed zone along roads network must be considered. Appropriate pathway cross between all the functions and sections. The installations must be considered for the carrying materials, in order to obtain the maximum performance for the food supplies and medicines, to ensure that the major functions are active. To get highly efficient spatial organization of the temporary housing, and the services, a number of factors should be studied.

- Space required per person and for each installation

- Accessibility of services

- Minimum distance required between facilities and shelters (Table 2).

- Cultural habits and social organization of the refugee population (clans and extended families)

- Ethnic and security factors, relationships among different sections/ members of the community, etc.

Cultural and social traditions are a determining factor in ensuring refugee acceptance of the infrastructure and services provided, particularly in regard to housing, sanitation, burial places, etc. However, as the layout that might be preferred by the refugees is not always the one that would allow the most efficient delivery of aid, site planning generally requires compromise solutions that take into account the different points of view.

Table 2: Some quantified emergency norms for site planning (Shelter and site planning, 2016)

\begin{tabular}{|l|c|}
\hline Camp Settlement Area per person & $30-45 \mathrm{~m}^{2}$ \\
\hline Shelter space per person & $3.5 \mathrm{~m}^{2}$ \\
\hline Number of people per water source & 250 \\
\hline Number of people per latrine & 20 \\
\hline Distance to water-point & $15 \mathrm{~m}$ max. \\
\hline Distance to latrine & $30 \mathrm{~m}$. \\
\hline Distance between water-point and latrine & $100 \mathrm{~m}$. \\
\hline Firebreaks & $75 \mathrm{~m}$. every $300 \mathrm{~m}$. \\
\hline Distance between two shelters & $2 \mathrm{~m} . \mathrm{min}$. \\
\hline
\end{tabular}

Essential installations are described in (Table 3). Some are likely to be centralized:

- Reception center 
- Health center

- Hospital

- Meeting place for home-visitors, etc.

Other facilities, such as health posts, latrines, washing areas, etc., should be decentralized. Care must be taken to ensure that there is sufficient space for such decentralized services in all the camp sub-divisions.

Table 3: Facilities needed to be considered

\begin{tabular}{l}
\hline Roads and firebreaks \\
\hline Water supply and sanitation facilities \\
(Defecation areas, latrines, waste disposal pits, washing places, etc.) \\
\hline Health facilities: health center, health posts, hospital, pharmacy and site for cholera camp. \\
\hline Meeting place for home-visitors \\
\hline Nutritional facilities: therapeutic and supplementary feeding centers \\
\hline Distribution site and storage facilities (in separate locations) \\
\hline Administrative center, reception area \\
\hline Other community facilities: market, schools, cemetery, meeting places, etc.
\end{tabular}

\subsection{The Layout of Shelters}

The purpose of establishing shelters is to protect the refugees from the outside environmental factors, and also to provide a privacy space for families, to give them the feel of secure. Some types of prefabricated shelter are still being tested and may be suitable for use in the first weeks of an emergency. Standard shelter space per person recommended in emergency is $3.5 \mathrm{~m}^{2}$ that is also could be changed according to the different culture's needs. In order to provide temporary shelters, there are several suggestions could be considered: The most common solution to construct temporary shelters is to let the refugees themselves make them, by local materials distributed by the responsible. In case of lack of local materials, tents are recommended to use for temporary short time. Public buildings "schools" may help, however. They are not recommended for large numbers, only work as temporary solution. After the emergency period has passed, the temporary shelters must be replaced with the permanent shelters (UNHCR, 2007).

The way that asylum is gathered has a significant impact in order to restore the social life, and the utility of latrines and water-points, and, security. "In general, the site should be divided into smaller units for management purposes. For example, it could be divided into sectors of 5,000 and sections of 1,000 people. However, the formation of such units must take into account the existence of any groups within the population which may be mutually hostile. Two principle methods for gathering asylums are described; courtyard type clusters and, lines and rows clusters. Courtyard type clusters the preferred as the site can be divided into basic community units, formed by the asylums and also the community facilities, (Washing areas, water-points and latrines) (Figure 2). Those essential units should be designed to be reached easily, and connected with refugees most needed. 


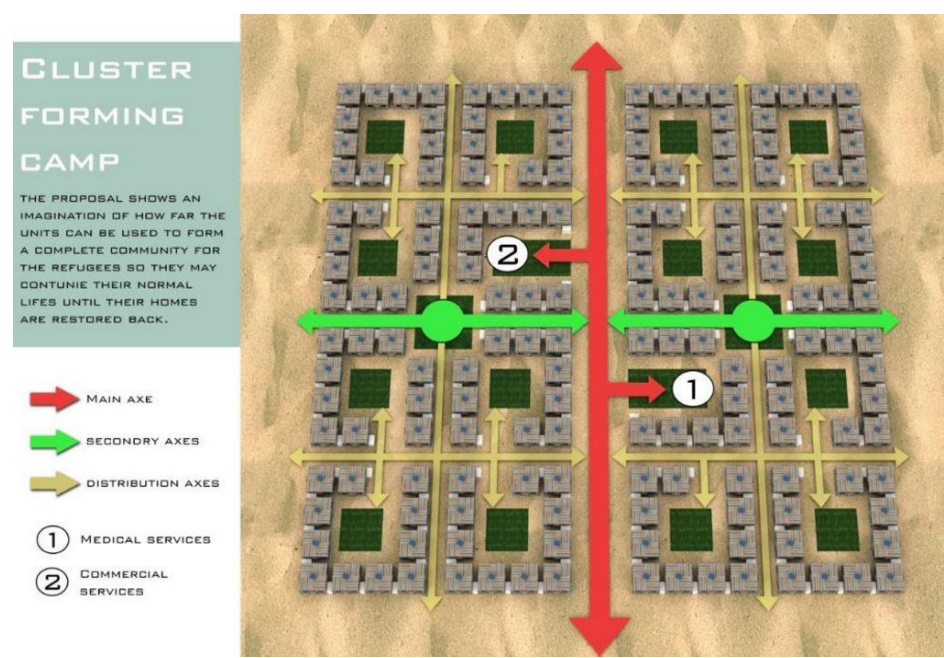

Figure 2: Basic community units, formed by the asylums and also the community facilities (Elcharkawi, 2010)

Lines and rows layout is the other possible option to establish, because this option prevents families of personal space, and maximize the range to latrines and water-points. This option selected because it's quick and efficient in the sudden cases, and overcome with the huge influx of refugees (Figure 3).

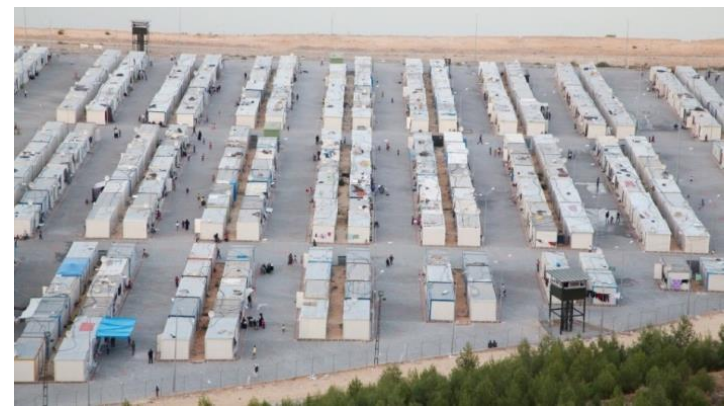

Figure 3: KILIS refugee's camp, (Hutzler, 2014)

\subsection{Health Facilities}

It is imperative that site planning is completed almost immediately in order to reduce health constraints, provide appropriate facilities and prevent the influx of refugees. In order to protect refugees from the surroundings, shelters should be provided quickly, accompanied by compulsory health and nutrition facilities, installation of water supply, latrines, etc. There are two likely scenarios that relief agencies frequently encounter, the first is that the camp is established in advance and the refugee population has settled quickly before relief agencies arrive. The second case is where, the relief agencies appear before the refugees have settled, allowing them to have more control of the situation. An example of this can be in the case of relocation or transfer of refugees from one camp to another. Weak decisions in the early phase may cause an unsteady situation with regards to camp organization, with knowing health concerns, therefore 
strict action must be taken in order to improve the site and its facilities. For instance, to avoid any hindrances such as congestion in the near future, site extension must be well thought out from the beginning. There has always been a debate whether funds should be used to sustain local communities who host refugees, or to establish refugee camps (UNHCR, 2007).

\subsection{General Management of Camps and Refugee Settlements}

Site planning must make sure to achieve reasonable space arrangement, as well as providing temporary housing and the facilities essential for passing on necessary goods and services. In order to accomplish this, proper management by specialists is required from different departments being; sanitation, geology, construction, etc. UNHCR is responsible for supervision of refugee site planning, however since they are not always readily available in regard to an internally displaced settlement, other agencies take control. For example, PDMA (Provincial Disaster Management Authority) was responsible for the Jalazoi camp. Health agencies must make sure that particular protocols that can a have a huge impact on health hazards are followed, even though they may not necessarily be involved in coordinating sites. It is therefore obligatory to have comprehensive knowledge of all fundamental principles in site planning (Express Tribune, 2012). Following proper guidelines, it is important to work out the most suitable site in advance. High density camps have a higher chance for disease transmission, as well as fire and safety concerns therefore they must be prevented. Camp, and integration into a local population are two main types of refugee settlements, they each individually have advantages and disadvantages. The advantages of camp are that it provides protection and asylum, which is important at that point in time. It is also easier to estimate population numbers and the needs of refugees as well as monitor their health status, and it more appropriate for temporary situations. Repatriation will be easier to plan, as well as permitting visibility and advocacy. However, on the contrary, there is an increased risk of outbreaks of communicable diseases due to overcrowding; this poses a colossal issue for the organizers as well as the displaced people. There may also be problems with degradation of the surrounding environment, security problems, lack of autonomy, and dependence on external aid. Consequences of social isolation need to be conducted expertly as the consequences may be remorseful (UNHCR Emergency Handbook,). When it comes to integration into a local population, the benefits are that it gives easy access to alternative foods, jobs etc. as well as helping refugees to have mobility. It provides the option of refugees to have access to existing facilities such as water and health, while also favoring refugee survival strategies. Additionally, it improves integration into the future by enhancing reconstruction of social/economic life. There can also be some disadvantages to integration, one being that it is difficult to reach the population, leading to problems in monitoring health needs. Knowledge of the local situation is required in order to be able to implement such relief programs. It may cause possible tension between local communities and the refugees therefore increasing the risk of destabilizing the local community.

In case of a disaster, whether natural or man-made, shelter is the only thing that matters. Immediate response is essential to assess the provisions already made and deliver material for temporary shelters. Shortly after the emergency phase is over, temporary 
shelters should no longer be used and more permanent shelters should be designed for the refugees. During the course of the shelter building programs, several limitations need to be taken into consideration. The renovation and restoration methods can be very expensive as well as quite time consuming. Extreme measures are sometimes taken in order to make the programs simpler in terms of management; this is partly due to the vast assortment of choices for constructing shelters. At times, local administration may obstruct refugees from staying for a longer duration and this may result conflict, as they are not in favor of permanent housing (semi). As a result, the job is rather unique and requires proficiency. Using local material is greatly endorsed however due to the fact that harm may be caused to the environment through deforestation; its accessibility might be a hindrance. Shelter building is crucial for surviving the conditions, in countries like Afghanistan or European countries due to the low temperatures recorded in the winters. It still remains a very complicated issue to handle in a crisis situation even though several considerations have been taken into account for example, installation of heaters and use of specialized winter tents. (UNHCR, 2007).

\subsection{Types of Camps}

Camps with shelters are subdivided into four types: spontaneous; collective; transit; and formal camps. Spontaneous camps are set up locality for a temporary period and are used in case of emergency, like floods and earthquakes. Formal camps usually accommodate refugees and IDP's and they are built for a longer period of time, between four to six months. Collective camps are set up in existing buildings, typically public, in case of an emergency or an immediate response situation. Whenever there is a fire, rain or other disasters, it has been observed over recent years, how people are evacuated from public schools in the neighborhood. Camps are also a temporary setup where people in dangerous situations stay together for a particular period of time. When a certain group of people are in the process of moving to a final destination, transit camps are set up for them. These usually happen in the outskirts of the city, away from all facilities (UNHCR Emergency Handbook). UNHCR's canvas tents are usually designed as temporary shelters; unfortunately they are the most common used in formal refugee camps. They provide more space than the lightweight shelters; also, they are made from 50 percent cotton and 50 percent polyester canvas, are waterproof and durable. But they aren't very livable, have no electric, no partitions, and no insulation (Figure 4, 5, 6) (UNHCR, 2007).

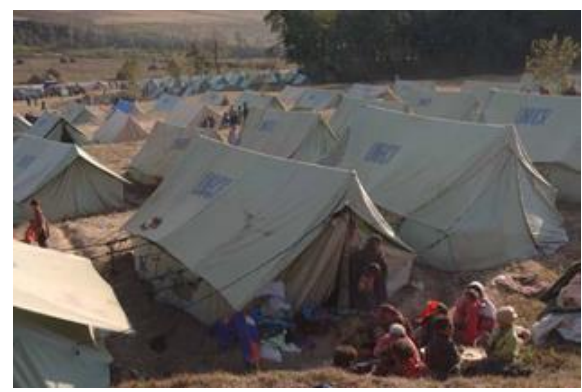

Figure 4: Transit camp(Al-Halabi, 2014) 


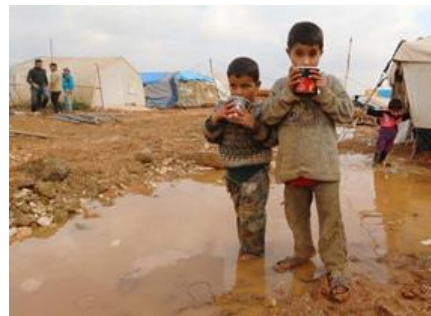

Figure 5: Displaced Syrian children stand in muddy water after heavy rains in the Bab Al-Salama Camp (AlHalabi, 2014)

As emergency housing for natural disaster and war victims, over the years, recycled shipping containers have been utilized. The insoluble exterior in combination with the solid structure makes it an ideal shelter for natural disasters, earthquakes and hurricanes (Figure 7). They are also used in designing attractive modular homes apart from the fact that they are frequently available and structurally-sound.

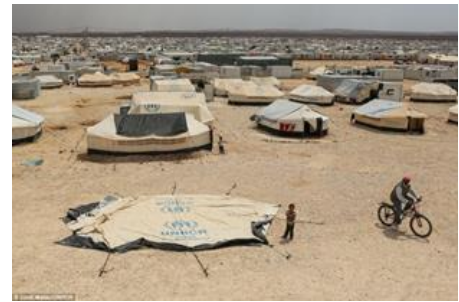

Figure 6: Upper view of canvas tents in Al Zaatari refugee camp (Malas, 2014)

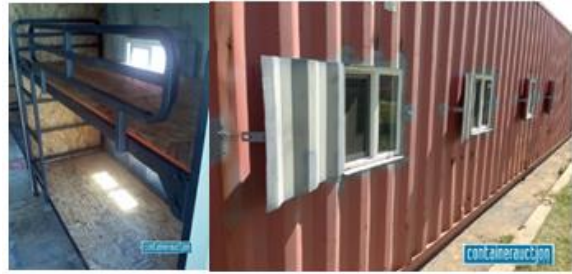

Figure 7: Two different views for shipping containers (Container auction, 2015)

Tents are being recently replaced by shipping containers in AlZaatari refugee camp and many old and existing camps which show the efficiency sustainability of the shipping containers. There are also camps designed as shipping containers camps. For example, Kilis in Turkey, Azraq in Jordan, Calais in France (Figure 8).

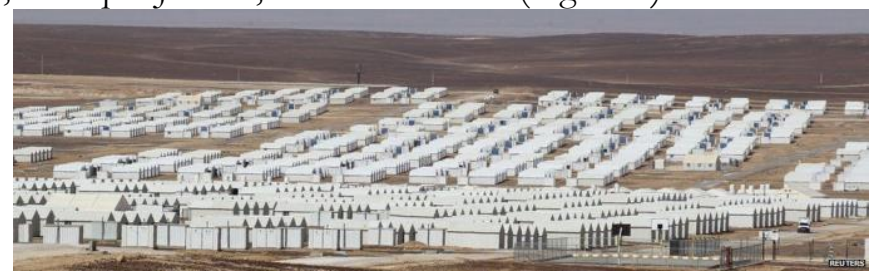

Figure 8: Perspective view for Azraq Refugee camp in Jordan (Knell, 2014) 


\section{Methodology}

After the literature review, in order to develop flexible shelter units which will be used as a long term residential unit in refugee's camps, the following steps are considered. Firstly $30 \mathrm{~cm}$ grid system has been preferred for unit plans as it's the recommended grid system for housing plans (Habraken, 1969). Secondly modular prefabricated materials are chosen. Thirdly modular shelter units according to family sizes are studied. Fourthly the modular shelter units are combined around courtyards to form clusters. Courtyards are preferred as they provide a good social communication among people. Courtyards are also efficient spaces in terms of climatic conditions. Particularly in hot climates where during day time shaded areas are needed. They also prevent spaces from heavy dusty wind. At the same time courtyards are good barriers for heavy cold winds during winter time (Farivarsadri and Dehghany, 2017).

\section{Modular Prefabricated Materials for Flexible Shelter Units:}

The chosen prefabricated materials for flexible shelter units are mainly studied as; modular steel structural system, wall panels and roof panels. The typical system for shelter units is shown in Figure 9. The composite roof panels consist of metal plate and heat insulation layers. Composite wall panels consist of compressed rice straw and insulation layers.

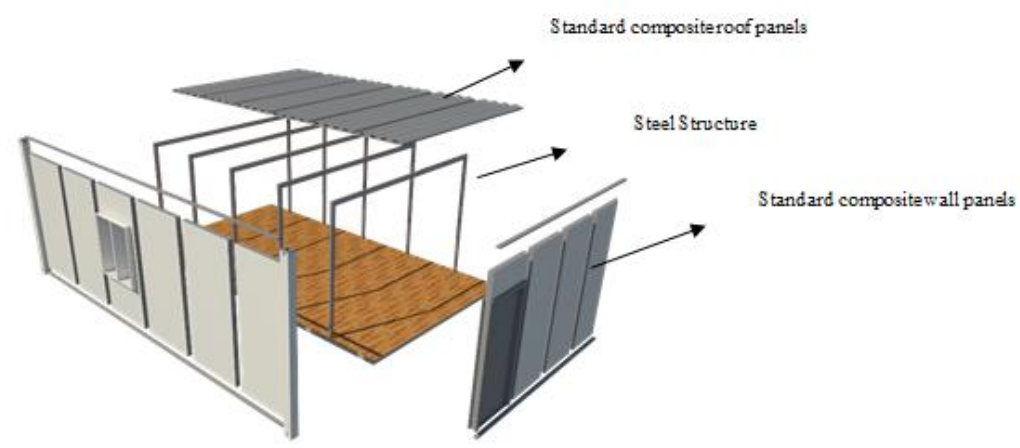

Figure 9: The typical structural system for Flexible shelter units

In this proposal solar panels for electric energy is also recommended; so that heavy investment for infrastructure is prevented (Figure 10).

Figure 10: Solar panels

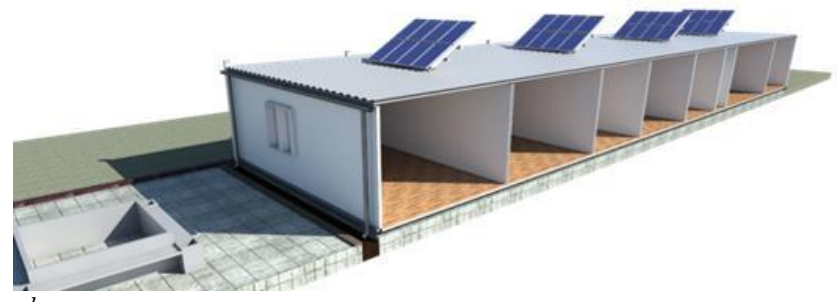




\subsection{Standard Panel dimensions:}

In order to make the system economic, panels' sizes (both for wall and roof panels) must be standard and as big as possible. They must be easy to carry and fix on site. In this study two standard panel sizes are preferred. These sizes are $90 \mathrm{~cm}$ and 120 $\mathrm{cm}$ which are at the same time multiples of $30 \mathrm{~cm}$. The combinations of these panels are expressed in (Figure 11).

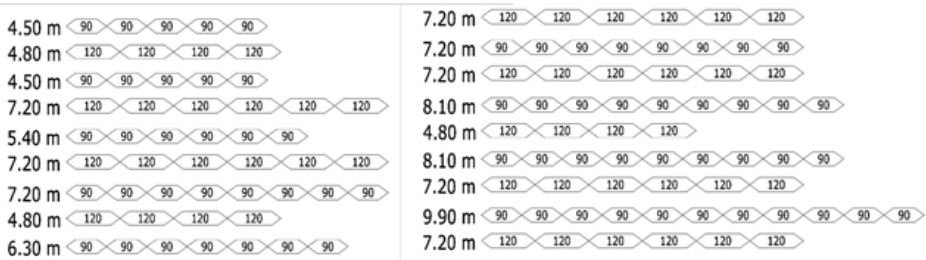

Figure 11: Combinations of two panels' sizes $(90 \mathrm{~cm}, 120 \mathrm{~cm})$ for planning of flexible shelter units

\subsection{Flexible Design of Shelter Units}

In this study according to family sizes and different needs developing flexible shelter units are aimed. On this basis, three types' single shelter units (Figure 12), three types two bedrooms units (Figure 13), three types three bedrooms units (Figure 14) with their three alternative arrangements.

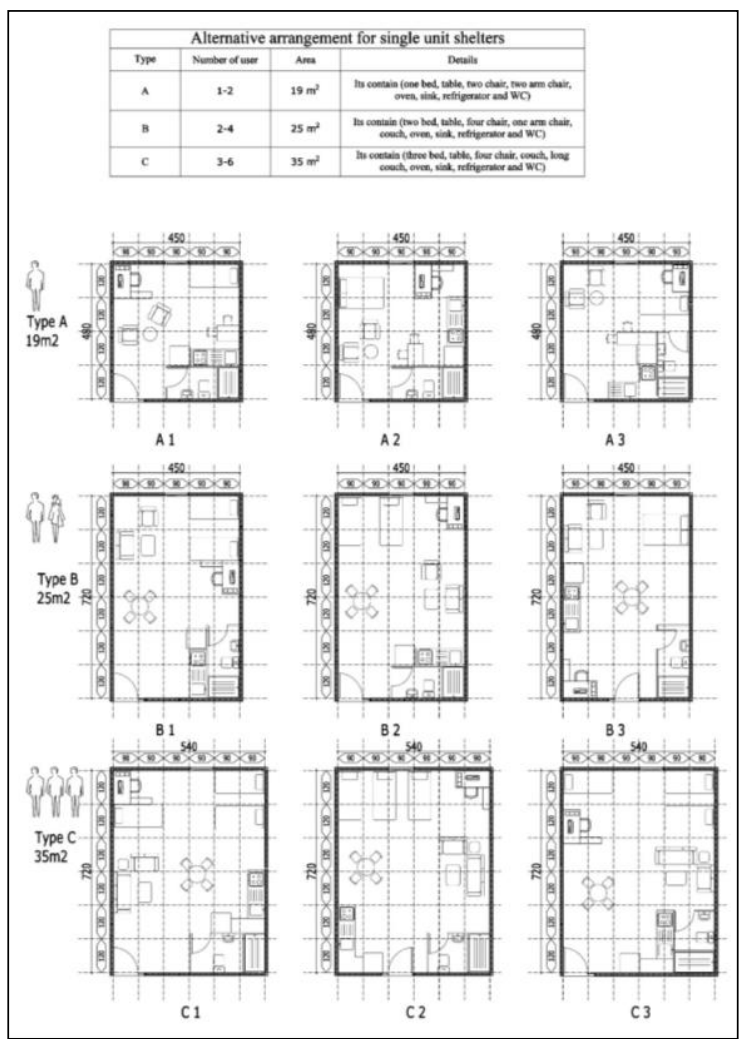

Figure 12: Alternative arrangement for single unit shelters 


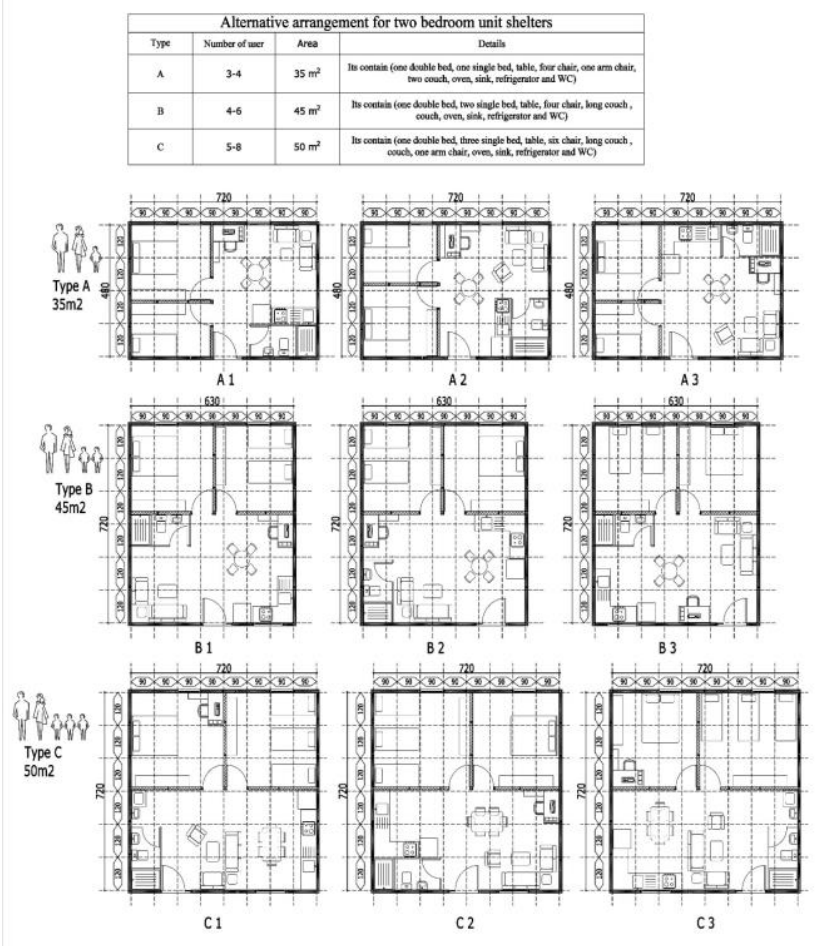

Figure 13: Alternative arrangement for two bedrooms unit shelters

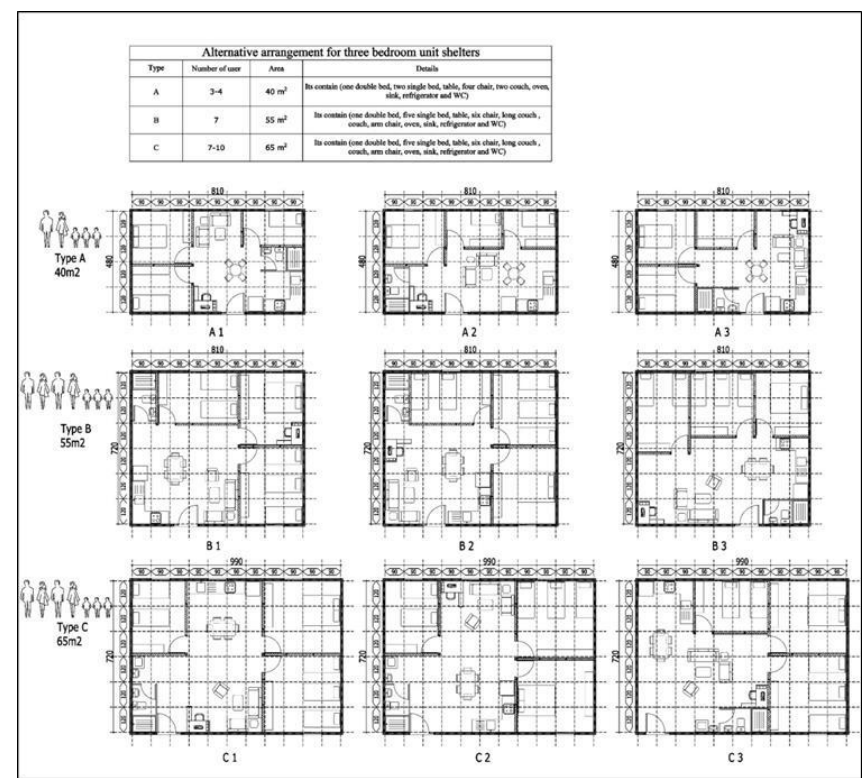

Figure 14: Alternative arrangement for three bedrooms unit shelters 


\subsection{Flexible Formation of Cluster Units}

Different shelter units can be combined in various ways to form courtyard clusters. Courtyards enables refugees to socialize. They can meet, communicate and help each other easily (Figure 15 and 16).

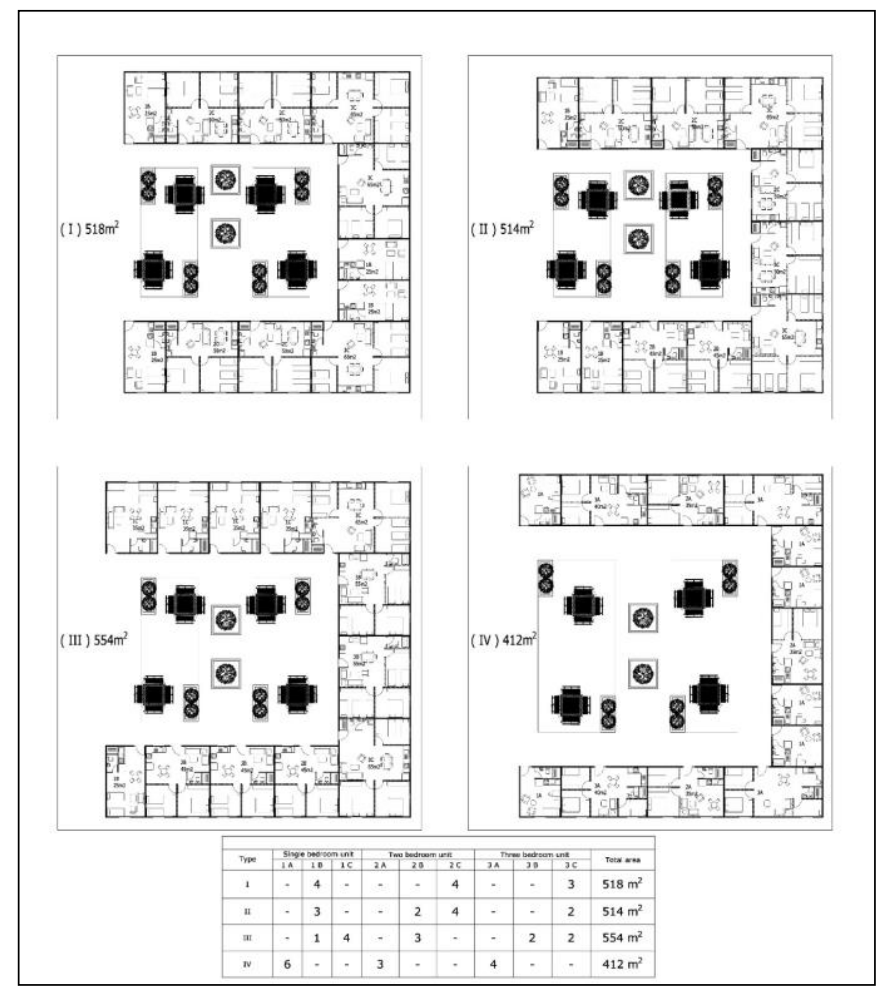

Figure 15: Flexible formation of cluster units

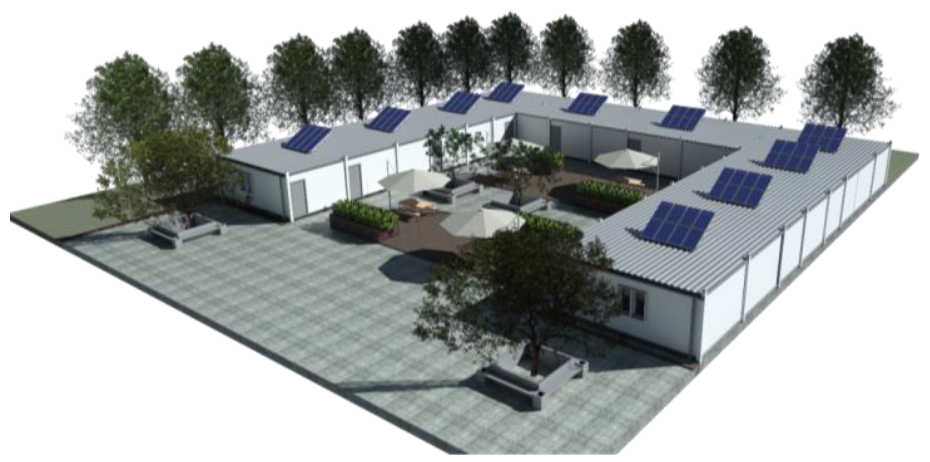

Figure 16: 3D of cluster units

\subsection{Flexible Development of Cluster Units in Urban Scale:}

As Rapoport (1982) says refugee's camps can well be developed such that qualified public, semipublic spaces together with semi private and private spaces can be 
harmonized. He says that particularly public and semipublic spaces are neglected in refugee's camps. (Farivarsadri and Dehghany, 2017). In this study modular flexible arrangement of cluster units enables planners to create qualified public and semipublic (Figure 17) spaces.

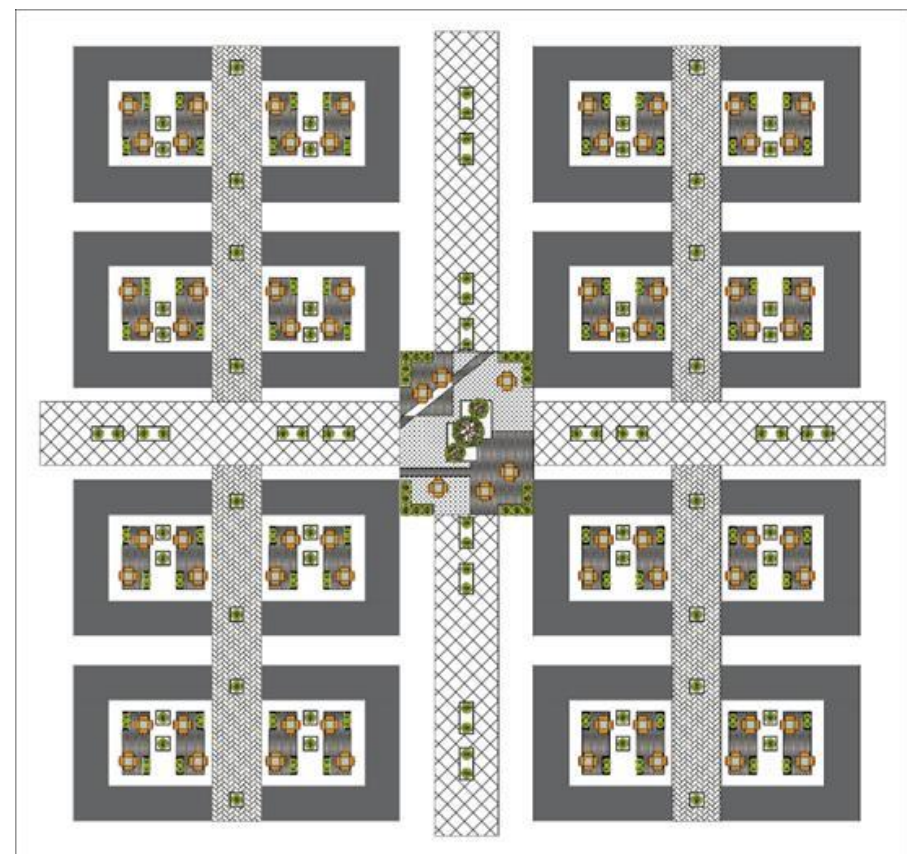

Figure 17: Development of cluster units in urban scale

\subsection{Practice on the Selected Site}

In this case study, the area chosen for sustainable refugees' camp will be inside of the country Azaz Syria and is accepted as safe. Azaz can be officially protected by the Turkish army, that's very good for the civilians or even for the displaced people who run to Azaz from all over the North of Syria. Azaz is a city in northwestern Syria, roughly 40 $\mathrm{km}$ northwest of Aleppo. According to the Syria Central Bureau of Statistics (CBS), Azaz had a population of 31,623 in the 2004 census.

The reason of choosing Azaz to establish the sustainable refugee camps inside it, first because of the advantages that Azaz takes in its position close to Turkey (only $15 \mathrm{~km}$ distance from Kilis). Secondly it has border gate with turkey called "Bab Alsalama" which plays a very big role in the Syrian conflict. According to the UN NEWS CENTRE "thousands of displaced people have gathered in Azaz in search of refuge close to the Bab Al Salam border crossing point, and thousands more are expected to arrive if the fighting continues. More than 30,000 people are reported to be on the move, many of them fleeing towards the Turkish border, and the towns of Azaz and Afrin." (UN NEWS, 2016).The food also transports on cross-border convoys from Turkey into Azaz and all of the north cities, which increase the advantages of making inner camps in Azaz. Especially, after the allegations that the Turkish government has recently made, that it 
will make safe area on its border with Syria included Azaz (Figure 18).

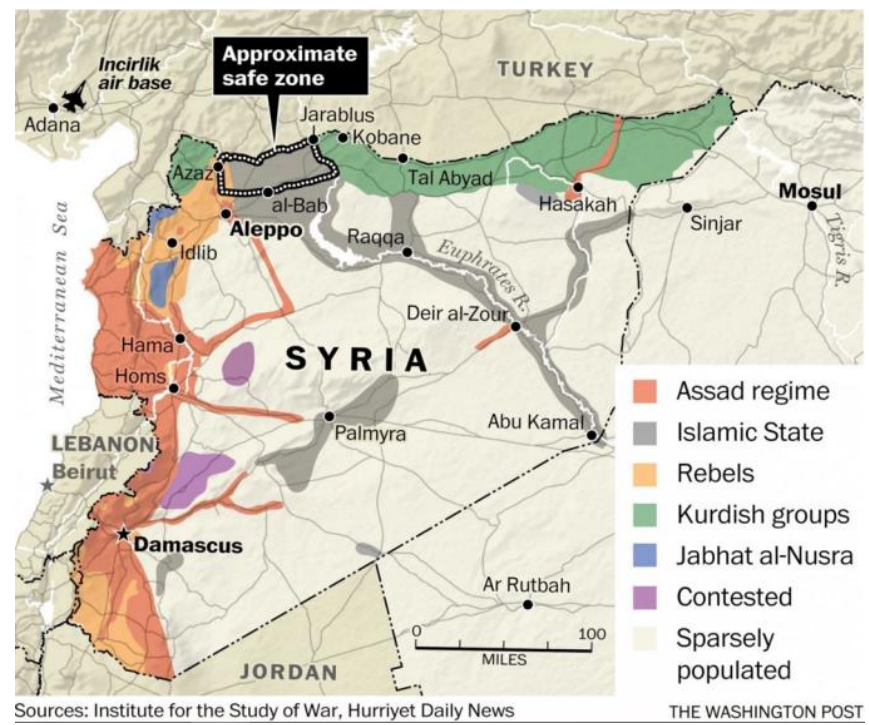

Figure 18: Syrian map (Institude for the study of war, n.d.)

Establishing an inner camp in Syria for the inner displaced, will give a solution inside and outside Syria for the refugee's crisis. According to UNHCR "Since the Syrian crisis began in 2011, Turkey - estimated to host over one million Syrians - has maintained an emergency response of a consistently high standard and declared a temporary protection regime, ensuring non-refoulement and assistance in 22 camps, where estimated 217,000 people are staying. Turkey is currently constructing two additional camps." (UNHCR, 2015). That shows the huge amount of the refugees in Turkey (Figure 19).

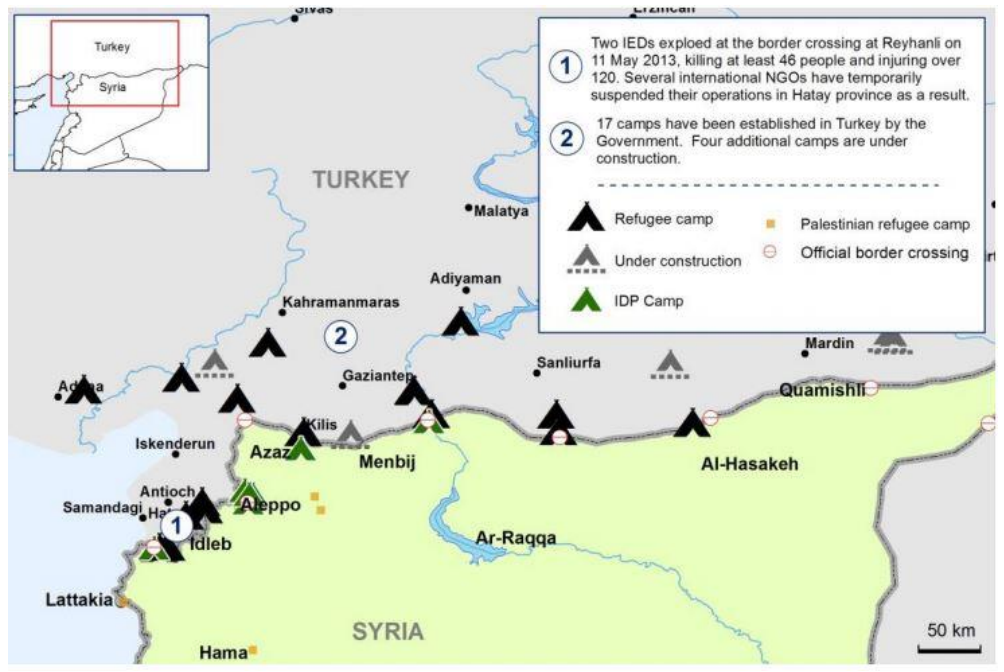

Figure 19: Refugee camps inside and outside Syria (UNHCR, 2013) 
Making a safe area in North Syria will make a huge different in the refugees crisis, because most of the refugees are from North Syria whom running from the war to Turkey. Establishing extendable sustainable camps in North Syria in safe area provided by Turkish army, with initial capacity of 240.000 refugees can stop those people from running to Turkey, or even to Europe. Also establishing camps in border area with Turkey will provide easy transportation for the essential goods and materials for the refugees and also for building camps. The site is available to make the camp sustainable, because it has got a very good soil for various plants and trees; however, it is very famous with olive trees. Its soil is very rich with water and nearby few water sources (Figure 20).

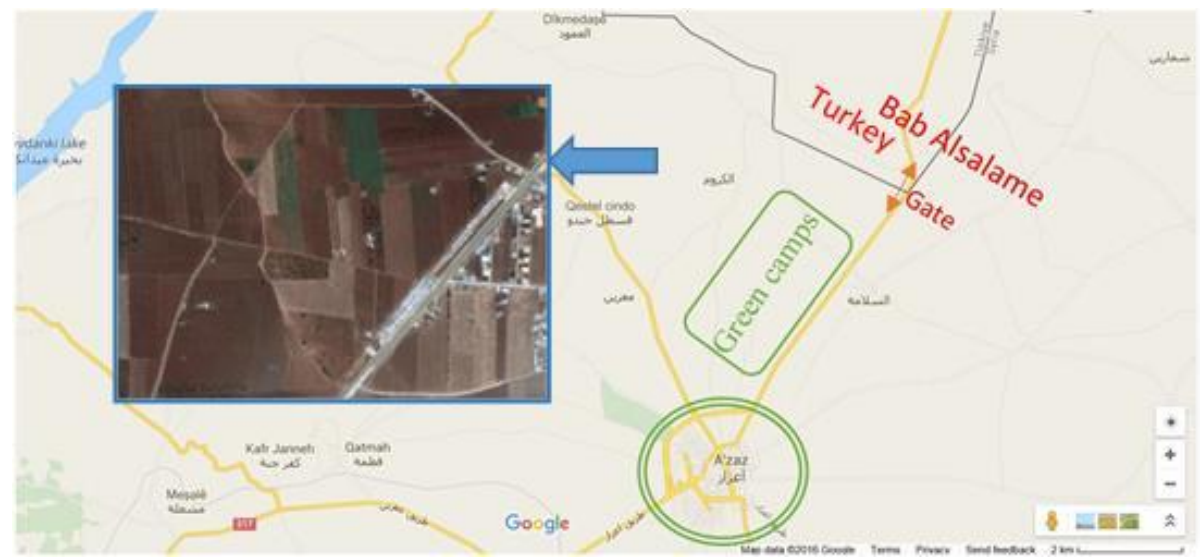

Figure 20: Selecting the refugee camp, and zoning

(bttps://www.google.com/maps/@,36.6016749,37.0476287,12.75z)

\subsection{Site Organization:}

Site planning of the camps needs to have specialists from all departments for example, geology, sanitation, architecture, construction, etc. Unfortunately, this coordination between all of these sectors is very hard in case of emergency sudden exodus. It's very important to form a confirmed standard flexible design for those kinds of sustainable camps planning. This type of approach may become a reference for any other expected exodus in any place in the world. This type of solution can be applicable and constructed extremely quickly in case of emergencies. And only low amount of changeable factors are left to be determined according to geographical and cultural variation. This modular practice in the study tries to analyze sustainable refugee's camps that can be established both inside and outside of the place of conflict.

The next step after choosing Azaz as a location to build the sustainable refugees camp, and made an abstract vision on how the main functions will be distributed, now it's the time to go deeper plan and design the camp in a way to ensure that all the facilities are set highly efficient. Everything must be studied and planned in such a way as, to achieve the goal of obtaining sustainable refugees camp. This step will show how all the facilities are arranged within the zoning into appropriate places to suit the function for each one of them, and also to take the most advantages of these facilities in order to help the 
refugees with all their needs. Some common spaces like courtyards can be created in order to let the refugees meet each other. Figure 20 shows the site organization of the camp. There are unit, plot, zone, section shown in the figure. When two sections gathered together, it is called as region.

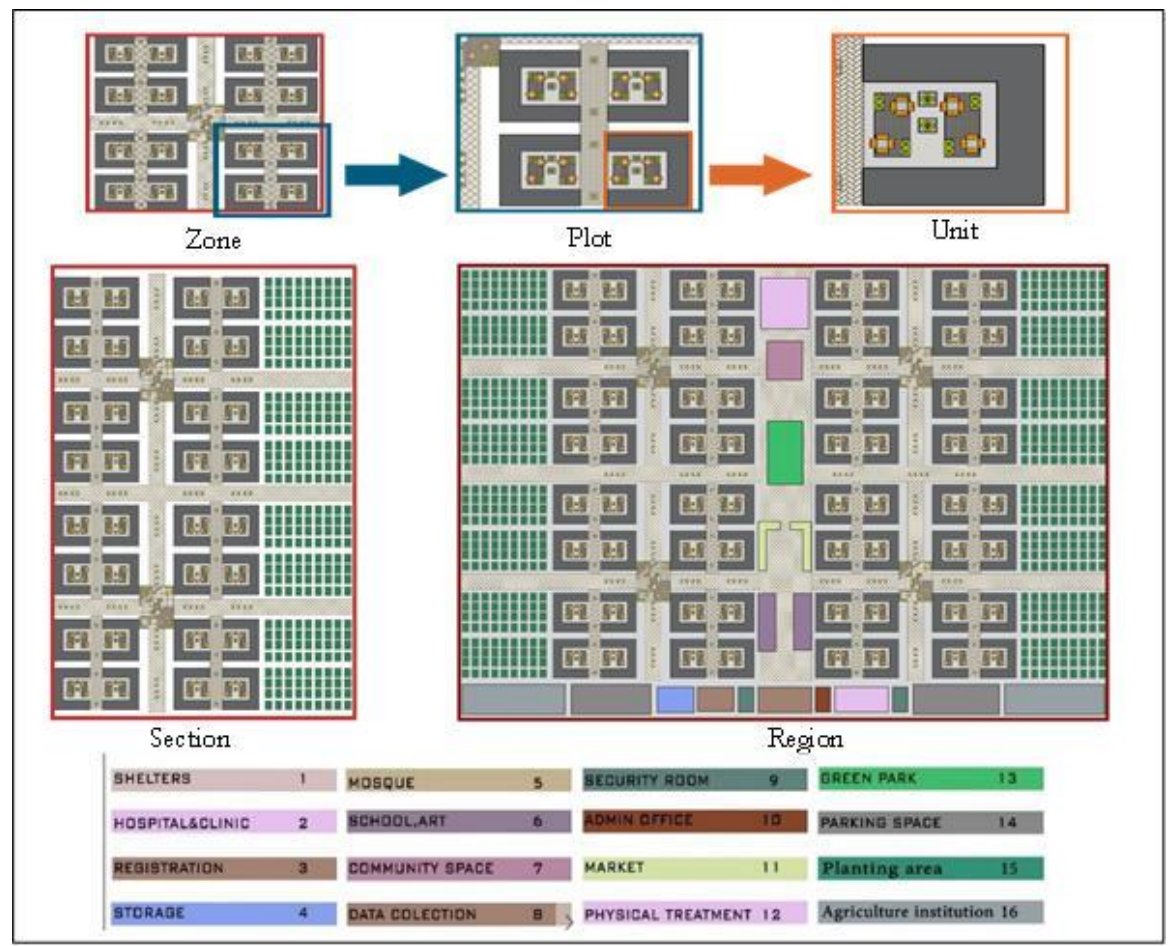

Figure 20: site organization of the refugee camp

The estimating capacity of one region is between 2550-2640, and this system of division gives the unlimited flexibility of extension. By repeating the REGION to fulfill any expected area and the capacity we have already chosen. In this study the expected amount of the inner refugees to come is 100,000 displaced people from all over Syria to Azaz, in this case the repeated number of region must be around 40 Region placed in Azaz. Exactly on the road which connects Azaz with the Turkish Gate border "Bab Alsalama".

This study gives opportunity to analyze and figure out the spaces needed by the persons living in camps. Hospital, mosques, schools, markets, parks, community spaces, and also security rooms should be considered in the urban design level to improve the sense of community. Creating open spaces and meeting points are essential considerations in order to have high level of interaction between the refugees which is very important to keep them to feel that they are normal people, and to let them communicate with each other, in a good friendly environment around them. Hospital can also be designed in an expandable way such that can be reached from inside and outside of the camp. The major health facility should be positioned in a secure and easily reached place. It is 
recommended on the periphery of the site in order not to have overcrowding and also to allow the expansion in the future. The required area can be determined by the capacity of the medical service to be provided. It is also very important to design space for sanitation and water facilities, as well as room for eventual expansion. The secondary health facilities should be located centrally in order to be reached easily in the areas they are served. The quantities usually determined by the size of population, according to the standards by UN (1 health post per 3000, 5000 refugees is required). Also, the schools located centrally in order to be approached by the teenagers easily. The green yards near the shelters let the kids to play under the supervision of their parents. The orientation of the whole camp has been established in a way that all the regions face the East, South, and West in order to take the maximum advantages of the Sun light, for producing the solar energy (Figure 21).

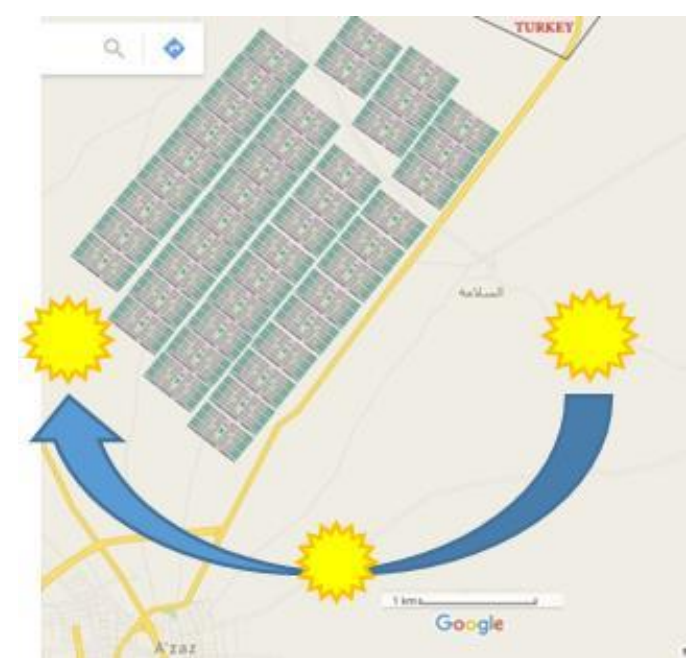

Figure 21: Planning all regions together

Camp can also be designed in such a way that, each shelter may own a small planting area. In order to encourage the refugees to plant their own vegetables and let them to be productive people (Figure 22). They may also socialize by making exchanges with each other.
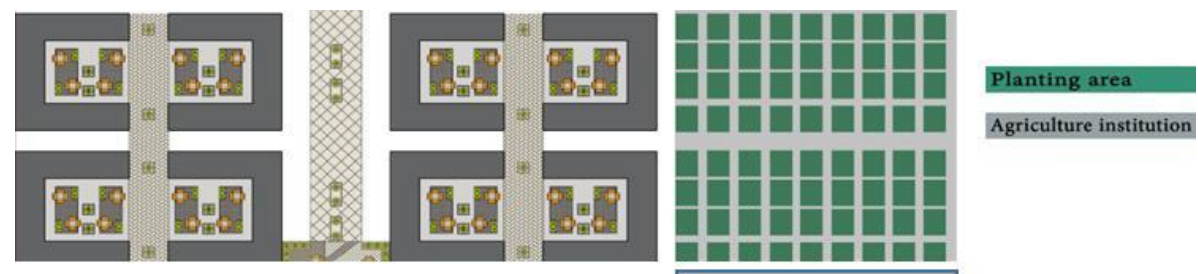

Figure 22: Planting areas

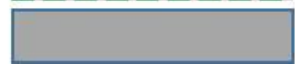

Agriculture institution

This social action is very important as it gives equipment (axes, seeds, handbook, special 
gloves, etc.) and forces refugees to produce and take responsibility. The agriculture institution should guide the refugees by giving them all the information they need. It should also help them by giving the manure and seeds needed. It is institution responsibility to analyze and balance the variation of the fruit and vegetable, planted by the refugees, in order to fulfill the needs of camp. Water network system which will collect all the clean wasted water can also be established. Waste water coming from shelters or public spaces can be used for irrigation of plants. This easy and inexpensive method will save tons of wasted unused water, to be used on other purposes without exhausting the drinking water sources. Also, the wasted food, vegetable, and fruit can be used in a way to convert them to efficient manure for the plants. Solar panels being part of sustainable approach can be located on each shelter's roof. The other alternative can be to create central solar fields. The system in general can be used to produce enough energy for the camp.

\subsection{Water availability}

Choosing a place for camp is very difficult, because in a country like Syria with so many cities are damaged and the other still considered as conflict cities, there are not so many choices to be taken. In this case study, the first priority was to find safe and border city, because in any country having a war, the priority is to save lives more than anything else. But on the other hand the water situation in Azaz is better than so many sub-districts in Aleppo Governorate. "Issues related to drinking water provision across assessed sub-districts of Aleppo Governorate tend to be impacted by various factors, notably the intensity of conflict which affects electricity supply to pumping stations and consequently the functioning of the whole water networks" (Reliefweb, 2015). Also, a survey made by the Reliefweb in each sub-district ranked the three following issues: access to water, availability of water, and quality of water by asking the people inside each sub-district (Figure 23).

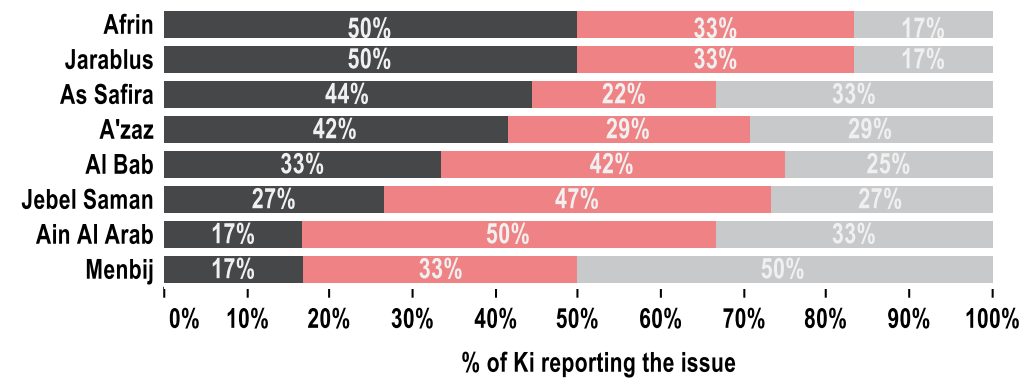

Water Quality

Access to Water

Availability of Water

Figure 23: Major Water issues in assessed districts of Aleppo Governorate (Reliefweb, 2014)

\subsection{Food availability}

All assessed sub-districts in Aleppo Governorate are currently facing extensive food shortages. Highest food severity levels were identified for Dayr Hafir and Rasm Haram El-Imam sub-districts in Al Bab district, Khanaser sub-district in As Safira district and Hadher sub-district in Jebel Saman district. In fact food security situation nowadays is remarkably effected across assessed sub-districts of Aleppo Governorate by 
various factors: the high level of conflict, hard to access, the distance from the Turkish gate border, the population density and the number of inner displaced people. These factors are affecting on the price of food products and may drive food insecurity up in areas where the population is heavily reliant on markets for food (Reliefweb, 2015). As the area is closer to Turkish border which is the main advantage, humanitarian aid can supply sufficient amount of food in a short-time. Besides, the next step will be encouraging the refugees to plant their vegetables by themselves under the supervision of agricultural institution.

\section{Discussion}

It should not be forgotten that living in the camps is not the choice of the refugees. These people were forced to live in these camps with limited freedom of movement, inadequate living, health and education conditions. It is the duty of all humanitarian organizations and authorities to improve these conditions and provide them with better living conditions. Refugee spaces should be designed as more humanistic spaces. Naturally, economic, technical, and functional matters are the main issues that need to be considered first in the organization and placement of camps. On the other hand, it is very important to improve the sense of belonging and community in terms of their psychological and social status. Architects also have duties to design more livable environments. International and national organizations working in this field must also understand the importance of this issue and go for a closer cooperation with the designers. Camp areas, should not be the places where only the functional aspects of temporary shelters are considered and where solid military ordnance of shelters are located. Camp areas must have public spaces where people can socialize. In addition, parks, gardens, and open public spaces can provide an environment for building healthier social relationships. At the same time, well designed squares, streets, urban elements can help in creating commitment to a place and being part of a community. Such measures may transform a temporary settlement into a permanent solution. Refugees, like all other people, have the right to live freely and honorably. Designers and architects can contribute to improve the quality of life of refugees by designing better housing and camp sites. Since it is a much more difficult process to improve the conditions of a camp after the settlement, the institutions responsible for this issue should actively involve the designers together with the users (refugees) in the decisionmaking stages in this process. In addition, architects need to use their knowledge and skills to design more humanistic camps.

As mentioned before, normally in case of war or environmental disasters, the displaced people are provided with temporary shelters and basic infrastructures, that's way the results are always disappointing at all levels. In this article, a study had been explained on refugee camp clusters which can be organized in a flexible way. Prefabricated wall and roof panels with dimensions of $90 \mathrm{~cm}$ and $120 \mathrm{~cm}$ are preferred and multiples of combinations are produced for alternative plans. Each alternative can satisfy the needs of refugee household according to their household (family) sizes. Within this flexible design, solutions are tried to produce answers for physical and psycho - social needs of refugees. Modular development of courtyard based clusters also enables various 
organizations at urban level design. The proposal focused on long term stay camps and recommends to use concepts of sustainability in the construction of refugees camps. By this approach, it can be recommended that refugee's camps can change of being heavy load and burden for the hosting country to a very productive and more sustainable settlement. Although, the aim of this study was to develop modular flexible shelter clusters for refugees such that they will satisfy both physical and psycho-social needs of their users, the camp planning approaches are also deeply studied and the psychological and the physical methods in urban level are encouraged to make the refugees camp more efficient. Organization of efficient physical environments or spaces can be meaningful if people are socially organized. Establishment of psychological health center to heal the refugees and qualifying the refugees to be able to work and becoming productive people must be one of the main targets in these camps. Enhancement of the common areas may reconnect people with each other and improve friendship feelings inside them. Considering all these, the physical conditions in the camps should support this philosophy. It should be noted that in most of the camps, refugees feel themselves as prisoners.

\section{Conclusion}

In this article, a synthesis of refugees family needs of different family sizes are studied within the frame of flexible modular clusters. The study also tries to show the possible growth of clusters can well be handled in urban scale, in order to create permanent settlement areas having common public and agricultural areas for social and economic aspects. Energy demand of the camps can be solved by renewable resources. Reuse of water and reuse of waste food solutions may bring many advantages from economic point of view for a long term stay camps. Planting of fruit and vegetables by the refugees themselves, can create small trades among them and give opportunity for getting extra income. Finding job is an important issue for refugees. They can work in the camp institutions and in other offices of the camp. The case study focused on Azaz Syria as inner refugee's camp where the refugees camp could handle more than 100,000 displaced people running from north Aleppo toward Turkey. It can be said that, by the proposed refugee camp made in Azaz, the displaced people crisis can be decreased significantly. It will also decrease the amount of the illegal emigrations to Europe. It is believed that modular flexible shelter clusters can satisfy refugee's physical and psychosocial needs. It is also believed that flexible modular approach and standardization provide economy.

\section{References}

Al-Halabi, B. (2014). Gov't Plan to Select Syrian Refugees by Religion Criticized, Displaced Syrian children stand in muddy water after heavy rains in the Bab Al- Salama camp. Retrieved March 21, 2015 from http://ottawacitizen.com/news/politics /govt-plan-to-select-syrian-refugees-by-religioncriticized

Arcan, E. F., \& Evci, F. (1992). Mimari Tasarıma Yaklaşım, Bina Bilgisi Çalışmaları. Mimarlık Kitapları Dizisi 1. İstanbul: $2 \mathrm{~K}$ Yayınevi. 
Containerauction. (2015). Containers company, two different views for containers. Retrieved January 15, 2016 from https://containerauction.com/read- news/housing-refugees-in-shipping-containers

Elcharkawi, M. (2010). Riba architecture, survivals columns. Retrieved October 30, 2015. Retrieved from http://www.presidentsmedals.com/entry-26291

Farivarsadri, G, \& Dehghany (2017). Mimarlı̆̆ın yeni sorunsalı: Mülteci konutları. Mimarc, 84, 52-62.

Habraken, N.J., Boekholt, J.T., Dinjens, P.J.M., \& Thijssen, A.P. (1969). Variations: The Systematic Design of Supports. Massachusetts: Laboratory of Architecture and planning at MIT, Cambridge, Mass 02139.

Hasgül, E., \& Özsoy, A. (2017). A living solution for refugees: Transient, modular and flexible sheltering systems. ENHR Conference 2017, Affordable Housing for All! Redefining the role of public and private sectors. Tirana, Albania.

Hutzler, T. (photographer). (2014, February 19). The New York Times Magazine sends Tobias Hutzler to Turkey for a cover story on "How to Build a Perfect Refugee Camp"[digital image].Retrieved from https://stocklandmartelblog.com/2014/02/19/new-york-times-magazine-tobias-hutzlerrefugee-camp/

Huynh, A. (2015). Emergency Urbanism Designing Refugee Camps in Jordan. Master Thesis, College of BuiltEnvironments University of Washington Seattle, Washington, US.

Institude for the study of war.(n.d.). U.S.-Turkey deal aims to create de facto 'safe zone' in northwest Syria. The Washington Post. Retrieved from https://www.washingtonpost.com/world/new-us-turkeyplan-amounts-to-a-safe-zone-in-northwest-syria/2015/07/26/0a533345-ff2e-4b40-858ac1b36541e156_story.html

Internal Displacement Monitoring Centre (IDMC). (2014).Syria: Norwegian Refugee Council. Retrieved February 08, 2015 from http://www.internal-displacement.org/middle-east-and-northafrica/syria/2014/displacement-in-syria-as-of-october-2014

Knell, Y. (2014). Azraq: How a refugee camp is built from scratch. Retrieved June 30, 2020 from https://www.bbc.com/news/world-middle-east-27205291

Malas, J. (2014). Upper view of canvas tents in Alzaatari refugee camp. Retrieved December 07, 2014 from http://www.dailymail.co.uk/news/article-2771866/My-visit-Syrian-refugee-camp-Jordanrevealed-unbelievable-heartbreak-hope-movie-mogul-HARVEY-WEINSTEIN.html

Oliveira, N. M. M., \& Campos, I, D. D. (2019). Flexible Refugee Shelter. IOP Conf. Series: Materials Science and Engineering 603. Retrieved July 3, 2020 from https://iopscience.iop.org/article/10.1088/1757-899X/603/3/032021/meta

Reliefweb. (2014). Key Informants Assessment Report, Syria Crisis-Aleppo City. Retrieved June 19, 2015 from http://reliefweb.int/report/syrian-arab-republic/syria-crisis-aleppo-city-key-informantsassessment-june-2014

Reliefweb. (2015). Assessment of the Needs and Humanitarian Situation within Syria, thematic situation analysis report. Retrieved October 10, 2015 from http://reliefweb.int/report/syrian-arabrepublic/assessment-needs-andhumanitarian-situation-within-syria-thematic

Shelter and Site Planning. (2016). Refugee camp building standards. Retrieved June 16, 2016 from http://www.webpal.org/SAFE/aaareconstruction/immediate/refugeecamp.htm\#when

UNHCR. (2013). Regional analysis Syria. Retrieved from https://data2.unhcr.org/ar/documents/download/38136

UNHCR. (2007). The UN Refugee Agency. Handbook for Emergencies. Third ed. Geneva: United Nations High Commissioner for Refugees, Feb. 2007. 